\begin{abstract}
"Mircea cel Batran" Naval Academy Scientific Bulletin, Volume XX - 2017 - Issue 2
The journal is indexed in: PROQUEST / DOAJ / Crossref / EBSCOhost/ INDEX COPERNICUS/ OAJI / DRJI I

JOURNAL INDEX / I2OR / SCIENCE LIBRARY INDEX / Google Scholar I Academic Keys / ROAD Open Access I Academic Resources / Scientific Indexing Services I SCIPIOI JIFACTOR
\end{abstract}

\title{
STUDY REGARDING THE USAGE OF ZUKERMAN-KUHLMAN QUESTIONNAIRE IN ANALYSING STUDENT SOCIALIZATION
}

\author{
Marcel POMOHACI ${ }^{1}$ \\ Sabin SOPA ${ }^{2}$ \\ ${ }^{1}$ Associate Professor PhD, "Lucian Blaga" University, Department of Environmental Science, Physics, \\ Physical Education and Sport, Ion Ratiu Street, No. 5-7, Sibiu, Romania \\ ${ }^{2}$ PhD Student, National University of Physical Education and Sport, Constantin Noica Street, No. 140, Sector \\ 6. Bucharest, Romania sopa sabin@yahoo.com
}

Abstract: Motor activities must be part of the global education of each student, through such activities the student manage to maintain muscle tonus and an optimal level of health, improving communication and social relationships, and positively changing their personality.

This paper aims to highlight the beneficial effects of motor activities on the personality of the students. So we started from the assumption that motor activities have effects on personality sphere on five levels: sociability and social integration, anxiety, sensation seeking, the level of aggression and activity level. We formed two samples of students $(N=25)$, the experimental group, with 12 girls and 13 boys, and the control group, 11 girls and 14 boys, both groups having children aged between 9 and 10 years. At the control group, we followed the curriculum and at the experimental group we used a training program that included with priority playful and agonistic means with dynamic games, stage races, games and sports competitions.

After applying the programs differentiated on the two groups we found using the Zuckerman-Kuhlman personality questionnaire, that students from the experimental group had a better level of sociability and social integration, low levels of anxiety, and that they are not so attracted of the new experiences, have a low level of aggressiveness and increased activity levels compared to the control group.

Keywords: motor activities, personality, socialization, social integration;

\section{Introduction}

Sport and physical education and sport can be considered very important tools of socialization and therefore any state bears a great responsibility to promote and develop those [1]. Another important contribution of the motor activities is their socializing role, demonstrated by many researchers from different fields saying that these activities represent the perfect framework in the social development process of young people [2].

Socialization through sport is a process of social integration through communication, understanding, and cooperation, with an interactive role for conflict resolution. Therefore, is structured on cognitive constructions, affective, and motivational as well as on representations, behaviors and performance of sports groups [3].

Also, sporting activities develop communication, intergroup relationships, and group cohesion. Motor activities can develop group cohesion positive intergroup relationships development, the discovery of group leader and most importantly integrate and reintegrate children into the social group. Group cohesion is very important in the evolution of school performance as a group, therefore in collectives where we have sympathy and positive relationships, work efficiency is high [4].

Motor activity is a component of active life, an "important link of lifestyle that generates the motion, according to their own options, several times a week, move that would make pleasure to consume energy and produce satisfaction" [5].

Related to physical education and its effects on group cohesion experts say the following: "Physical education can also improve the cohesion of groups having a good cohesion of the group is considered important and may lead to better performance. The relationship between cohesion and performance has been studied by many specialists, the majority concluded that "the connection between performance and group cohesion is mutual" [6].

Groups or successful teams are built around strong leaders and the importance of this role is growing in the nowadays sport in all categories [7]. Situational factors are important for the cohesion like leaving close to each other, sharing the same hobbies and activities, the same uniforms or clothing, group rituals etc. [8].

Lot ofaptitudesare taught by young people with the help of team sports, one of them iseven the competition. Nowadays we encounter competition every day and in every field. As adults we encounter competition when we look for a job or trying to find better jobs, at school children encounter competition for notes [9].

Shown like a social institution, sports activity has a good basis in society, has regulations, specific laws, ways of sanctioning, binding friendships 


\section{"Mircea cel Batran" Naval Academy Scientific Bulletin, Volume XXI - 2017 - Issue 2 The journal is indexed in: PROQUEST / DOAJ / Crossref / EBSCOhost/ INDEX COPERNICUS/ OAJI / DRJI I JOURNAL INDEX I I2OR / SCIENCE LIBRARY INDEX / Google Scholar I Academic Keys I ROAD Open Access I Academic Resources / Scientific Indexing Services I SCIPIOI JIFACTOR}

(both social and cultural) and communication systems, principles and ideologies [10].

Next to family, the first and most important social group, other groups helpsto the process of socialization of individuals: classmates, the group of friends and later professional staff. One of the ways that socialization within the group of friends or colleagues is done is sports. Individuals learn through sport to work together, to assume certain roles within the group and to define themselves in it [11].

Socialization through sport is a complex process through which individuals learn skills, attitudes, values and modesof conductwhich allowsfunctioningin a given culture. These modes of behavior are taught in institutions like school or family [12].

\section{The aim of the study}

The research had as primary objective the analysis of motor activities effects of the five areas analyzed by Zuckerman-Kuhlman Personality Questionnaire: sociability and social integration, anxiety, sensation seeking, the level of aggressiveness and activity level.

\section{The objective of the research}

The objective of this research was applying the Zuckerman-Kuhlman Personality questionnaire on the two samples of students and analyzing their results and progress.

\section{Study hypothesis}

The use as a research tool of the Zuckerman Kuhlman personality questionnaire can give us the opportunity to investigate the personality traits of students present in both the experimental group and control group in terms of sociability and social integration, anxiety, looking for sensations, and the aggression and activity level.

\section{Methods of research}

In the experimental research we chose a questionnaire commonly used in the literature on psychosocial research and personality, called Zuckerman-Kuhlman Personality Questionnaire.

The Zuckerman-Kuhlman questionnaire [5] aims to analyze the five dimensions of personality: the socialization and social integration of the individual (SY), neuroticism-anxiety (N-Anx), seeking impulsive sensations (ImpSS), aggression, hostility (Agg-Host) and activity (Act).

Zuckerman-Kuhlman questionnaire can be the analysis model for personality, the model which can analyze the personality behaviors and basal factors of students. In previous models, literature, psychologists have tried to propose different models of basal factor analysis of personality, supporting some version of the three factors variant [13], other of the five factor variant [14].

From all these models the model most used is the five factors model of Zuckerman-Kuhlman questionnaire.

Other research methods were: bibliographic method, statistical and mathematical method.

\section{Results}

Appling the Zuckerman-Kuhlman psychological questionnaire we managed to establish the psychological profile of each student of the two groups, experimental and control. Statistical interpretation of data obtained was performed using SPSS 22, performed on each scale.

\section{The sociability and social integration of the individual}

In the case of items that focused on the scale of sociability, analyzing the responses of the two groups, experimental and control, we concluded that $72 \%$ of students in the experimental group and $68 \%$ of students in the control group, obtained at the T-test a $\mathrm{T}$ quota within the average population.

Applying the significance T-test, we noticed that the p-value calculated was 0.00001 , below the value of $T(-10.907800)$, indicating a significant difference between the two groups of students.

Analyzing the results of the application of the Zuckerman-Kuhlman test on the sociability scale, we have seen that $8 \%$ of the experimental group students prefer individual activities and their results are considered best when working alone. In the control group, we noticed a larger number of students who prefer individual activities, and $20 \%$ of all students of the control group.

We achieved high scores of about $20 \%$ of the students of the experimental group and $12 \%$ of those from the control group at the top of the scale, which may indicate the presence of many friendships. 
"Mircea cel Batran" Naval Academy Scientific Bulletin, Volume XXI - 2017 - Issue 2 The journal is indexed in: PROQUEST I DOAJ / Crossref / EBSCOhost/ INDEX COPERNICUSI OAJI / DRJI I JOURNAL INDEX / I2OR / SCIENCE LIBRARY INDEX / Google Scholar I Academic Keys / ROAD Open Access I Academic Resources / Scientific Indexing Services / SCIPIOI JIFACTOR

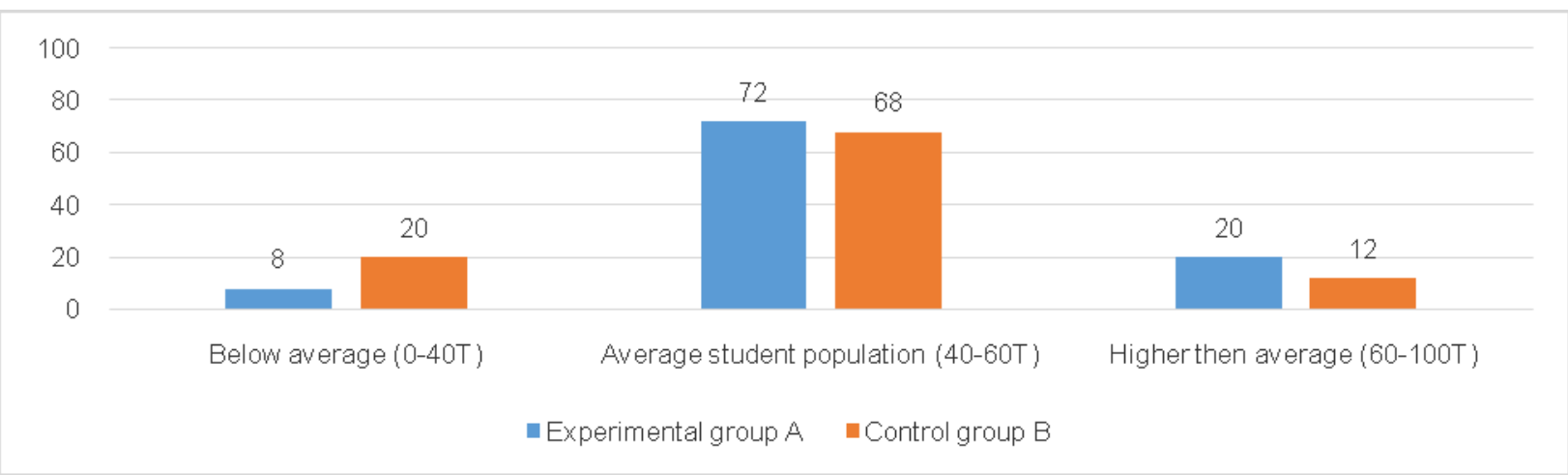

Figure No. 1 - The scaleof sociability and social integration

Table No. 1 - Statistical indicators of the sociability and social integration scale

\begin{tabular}{|c|c|c|c|c|c|}
\hline \multicolumn{3}{|c|}{ Experimental group A } & \multicolumn{3}{|c|}{ Control group B } \\
\hline $\begin{array}{l}\text { The scale of sociability and } \\
\text { social integration }\end{array}$ & Cases & $\%, N=25$ & $\begin{array}{l}\text { The scale of sociability and } \\
\text { social integration }\end{array}$ & Cases & $\%, N=25$ \\
\hline Below average (0-40T) & 2 & $8 \%$ & Below average (0-40T) & 5 & $20 \%$ \\
\hline Average population (40-60T) & 18 & $72 \%$ & Average population (40-60T) & 17 & $68 \%$ \\
\hline Over average (60-100T) & 5 & $20 \%$ & Over average (60-100T) & 3 & $12 \%$ \\
\hline Total & 25 & $100 \%$ & Total & 25 & $100 \%$ \\
\hline Mann-Whitney U Test & \multicolumn{5}{|c|}{ Z-score $=2.4933$ U-value $=183.5 \quad p$-value $=0.01278 \quad p \leq 0.05$} \\
\hline Test-T & \multicolumn{5}{|c|}{$p$-value $=0.00001 \quad$ T-value $=-10.907800$} \\
\hline One-Way ANOVA & \multicolumn{5}{|c|}{ f-ratio $=7.89464$} \\
\hline
\end{tabular}

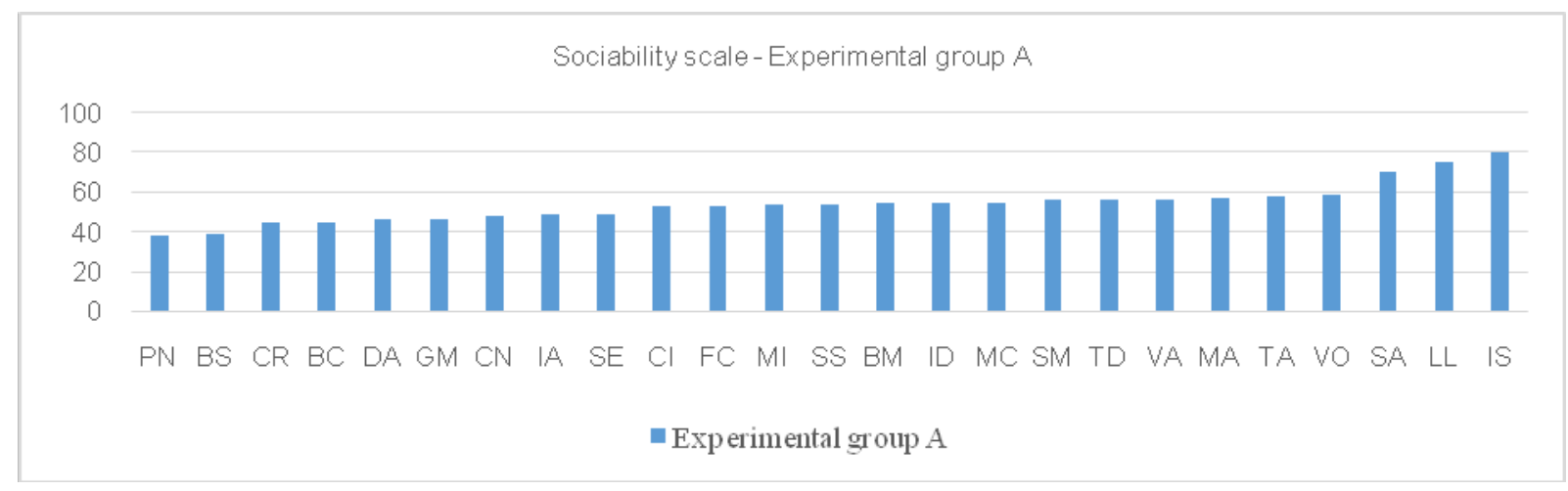

Figure No. 2 - Sociability scale - Experimental group A

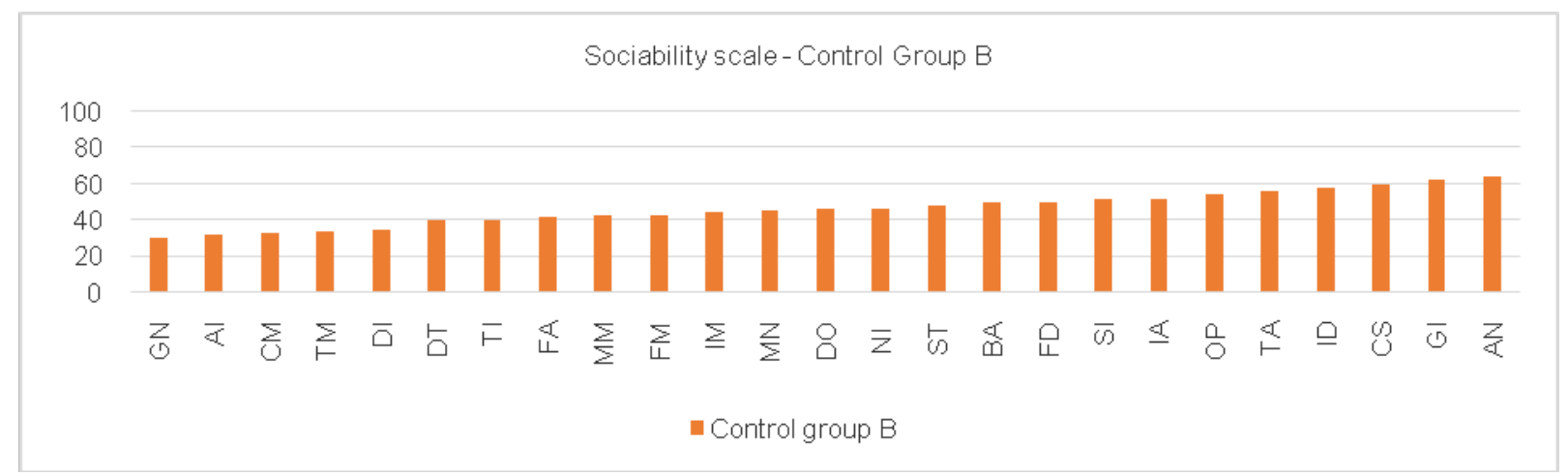

Figure No. 3 - Sociability scale - Control group B 
"Mircea cel Batran" Naval Academy Scientific Bulletin, Volume XXI - 2017 - Issue 2 The journal is indexed in: PROQUEST I DOAJ / Crossref / EBSCOhost/ INDEX COPERNICUS/ OAJI / DRJI / JOURNAL INDEX / I2OR / SCIENCE LIBRARY INDEX / Google Scholar / Academic Keys / ROAD Open Access / Academic Resources / Scientific Indexing Services / SCIPIO/ JIFACTOR

\section{Neuroticism-Anxiety}

In the case of items that focused on neuroticism-anxiety scale, we watched emotions, worries, anxiety level and distrust of the students in the two groups. Significant scores show the sensitivity of the subject, distrust in their own forces, and the level of anxiety. So analyzing the responses of the two groups, the experimental group, and the control group, we concluded that $48 \%$ of students in the experimental group and $46 \%$ of control group students are in the average population.

Applying the significance test T-test, we noticed that the value of $t$ was 4.471485, higher than the $p$ value of 0.000159 , indicating a significant difference between the two groups of students, $p \leq 0.05$.
Analyzing the results of the ZuckermanKuhlman test application, on the neuroticismanxiety scale, we have seen that $40 \%$ of students in the experimental group have no fears, worries or other anxieties.

In the control group, we noticed a larger number of pupils who are fearful, worried or have high levels of anxiety, at $24 \%$ of all students from the control group.

Regarding the upper part of the chart representing students with a high level of anxiety, we have scores of $12 \%$ of the students from the experimental group, compared with $28 \%$ of those from the control group, which may indicate a high level of resistance to stress, and a lower level of fear and anxiety in experimental group compared to the control group.

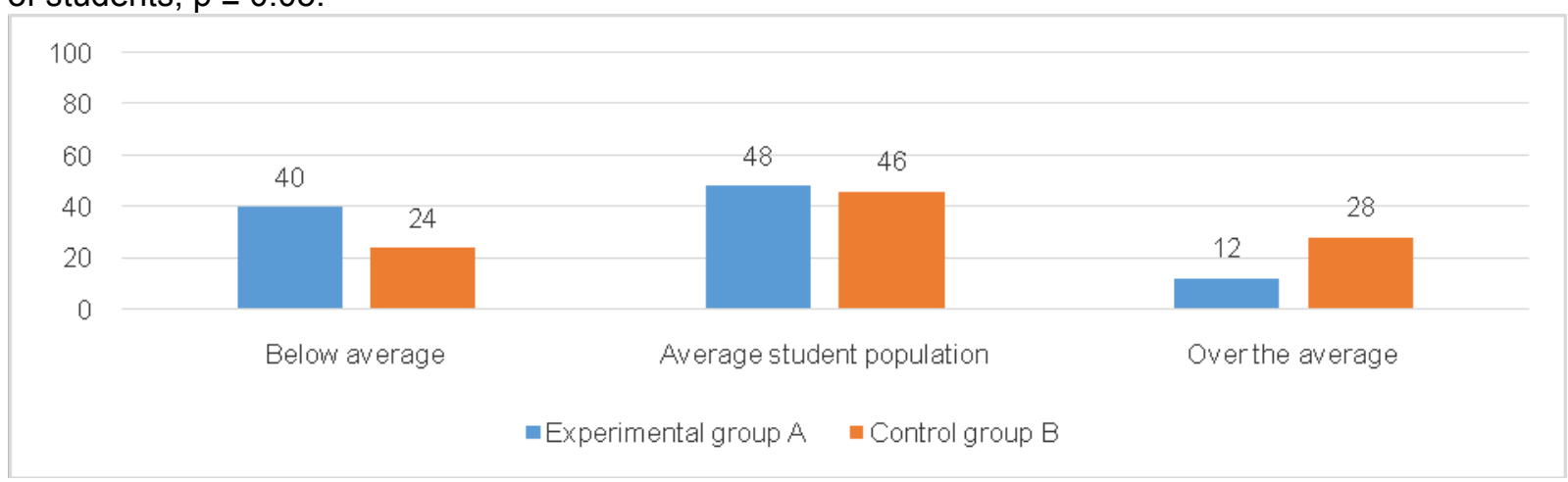

Figure No. 4 - Neuroticism-anxiety scale

Table No. 2 - Statistic indicators of neuroticism-anxiety scale

\begin{tabular}{|c|c|c|c|c|c|}
\hline \multicolumn{3}{|c|}{ Experimental group } & \multicolumn{3}{|c|}{ Control group } \\
\hline Neuroticism-anxiety & Cases & $\%, N=25$ & Neuroticism-anxiety & Cases & $\%, N=25$ \\
\hline Below average (0-40T) & 10 & $40 \%$ & Below average (0-40T) & 6 & $24 \%$ \\
\hline Average population (40-60T) & 12 & $48 \%$ & Average population (40-60T) & 11 & $46 \%$ \\
\hline Over average (60-100T) & 3 & $12 \%$ & Over average (60-100T) & 8 & $28 \%$ \\
\hline Total & 25 & $100 \%$ & Total & 25 & $100 \%$ \\
\hline Mann-Whitney U Test & \multicolumn{5}{|c|}{ Z-score $=-1.0478 \quad$ U-value $=258 \quad p$-value $=0.29372 \quad p \leq 0.05$} \\
\hline Test-T & \multicolumn{5}{|c|}{$\mathrm{p}$-value $=0.000159 \quad$ T-value $=4.471485$} \\
\hline One-Way ANOVA & \multicolumn{5}{|c|}{ f-ratio $=2.2064 \quad p$-value $=0.143978$} \\
\hline
\end{tabular}

Figure No. 5 - Neuroticism-anxiety scale - Experimental group A 
"Mircea cel Batran" Naval Academy Scientific Bulletin, Volume XXI - 2017 - Issue 2 The journal is indexed in: PROQUEST I DOAJ / Crossref / EBSCOhost/ INDEX COPERNICUSI OAJI / DRJI / JOURNAL INDEX / I2OR / SCIENCE LIBRARY INDEX / Google Scholar I Academic Keys / ROAD Open Access / Academic Resources / Scientific Indexing Services / SCIPIO/ JIFACTOR

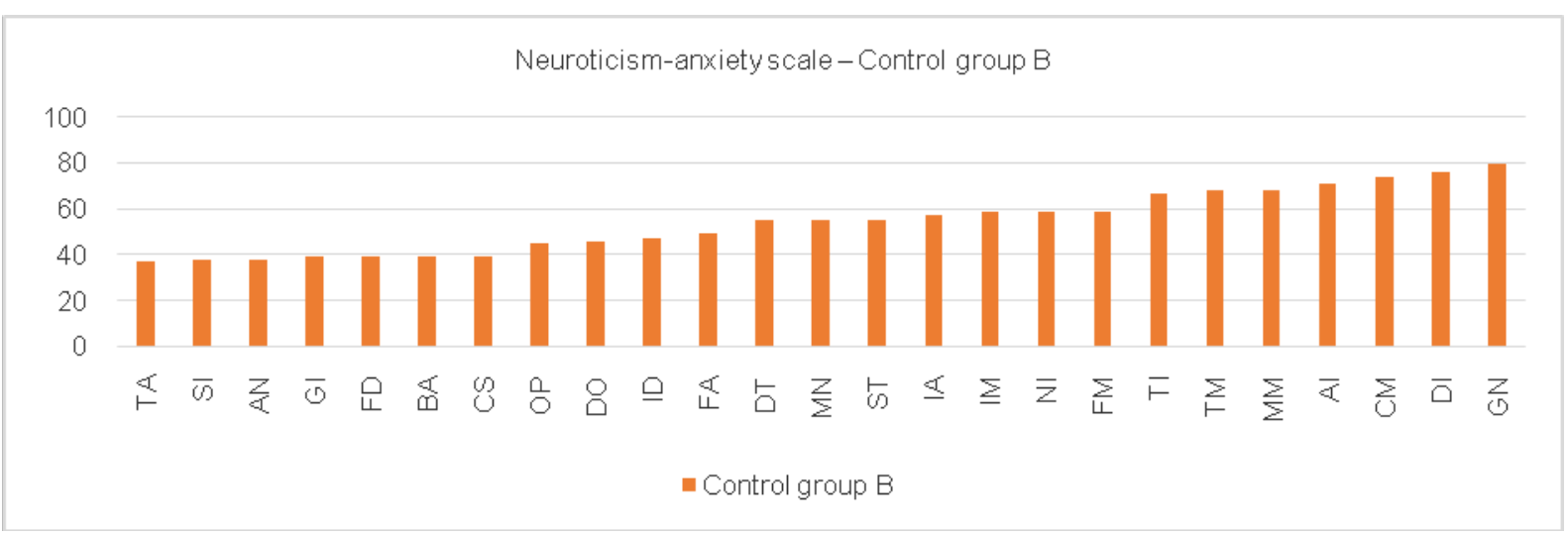

Figure No. 6 - Neuroticism-anxiety scale - Control group B

\section{Impulsive search of sensations}

In the case ofitemsthat focused on impulsive scale search of sensations, we followed the subject need of new, characteristicof those to impatience, rapid response and impulsive without prior reflection, unexpected, spontaneous, unpredictable.

Therefore analyzing the responses of the two groups, the control group, and the experimental group, we concluded that $60 \%$ of students in the experimental group and 58\% students of the control group have obtained a quota $\mathrm{T}$ below the average population.

Applying the significance test we noticed that the value of $t$ was 11.037062 , higher than the $p$ value of 0.00001 , indicating a significant difference between the two groups of students, $p \leq 0.05$.

Analyzing the results of applying the Zuckerman-Kuhlman test on the scale of the impulsive search of sensations, we have seen that $20 \%$ of students in the experimental group tend to not seek thrills or to hasty decisions, they are not anxious, thinking clear, imperceptibly need for contingency. In the control group, we observed a higher rate number of students with impulsivity and sensation seeking, up to $16 \%$ from the total of the students.

We obtained lower scores in the case of the experimental group, approximately $20 \%$ of students, compared with $24 \%$ of those from the control group regarding students who need sensational, unexpected, being impulsive and uncontrollable. Therefore we can say that motor activities have influenced the students from the experimental group to be more patience, being more calculated, more attentive, more disciplined, compared with those from the control group.

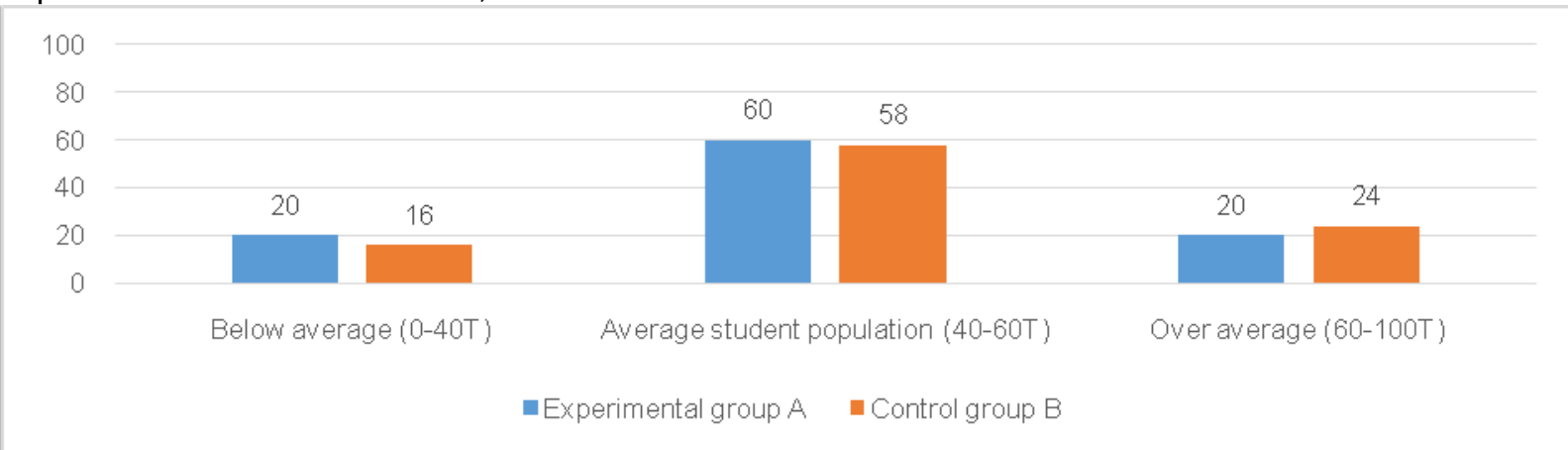

Figure No. 7 - Impulsive search for sensations

\begin{tabular}{|c|c|c|c|c|c|}
\hline \multicolumn{3}{|c|}{ Experimental group } & \multicolumn{3}{c|}{ Control group } \\
\hline $\begin{array}{c}\text { Impulsive search for } \\
\text { sensations scale }\end{array}$ & $\begin{array}{c}\text { Case } \\
\mathrm{s}\end{array}$ & $\begin{array}{c}\%, \mathrm{~N}= \\
\mathbf{2 5}\end{array}$ & $\begin{array}{c}\text { Impulsive search for } \\
\text { sensations scale }\end{array}$ & $\begin{array}{c}\text { Case } \\
\text { s }\end{array}$ & $\%, \mathbf{N}=\mathbf{2 5}$ \\
\hline Below average (0-40T) & 5 & $20 \%$ & Below average (0-40T) & 4 & $16 \%$ \\
\hline
\end{tabular}

DOI: 10.21279/1454-864X-17-12-022

(C) 2015. This work is licensed under the Creative Commons Attribution-Noncommercial-Share Alike 4.0 License. 
"Mircea cel Batran" Naval Academy Scientific Bulletin, Volume XXI - 2017 - Issue 2

The journal is indexed in: PROQUEST I DOAJ / Crossref / EBSCOhost/ INDEX COPERNICUSI OAJI / DRJI I JOURNAL INDEX / I2OR / SCIENCE LIBRARY INDEX / Google Scholar I Academic Keys / ROAD Open Access I Academic Resources / Scientific Indexing Services / SCIPIOI JIFACTOR

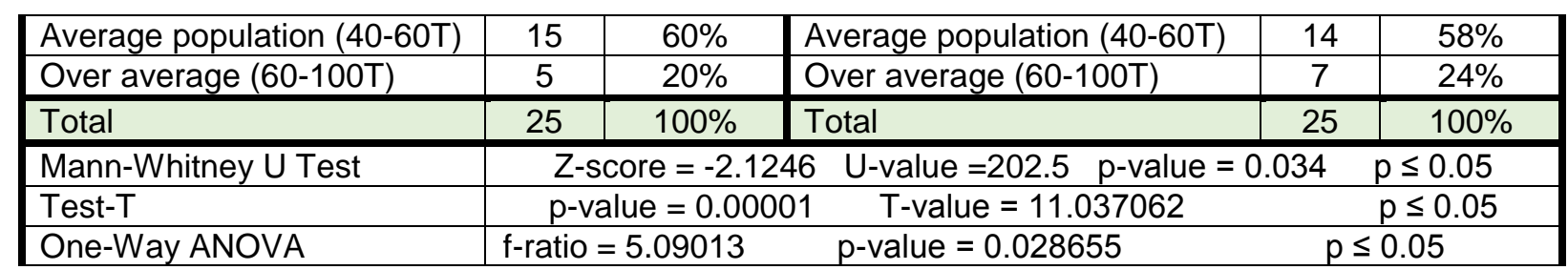

Table No. 3 - Statistic indicators of impulsive search for sensations scale

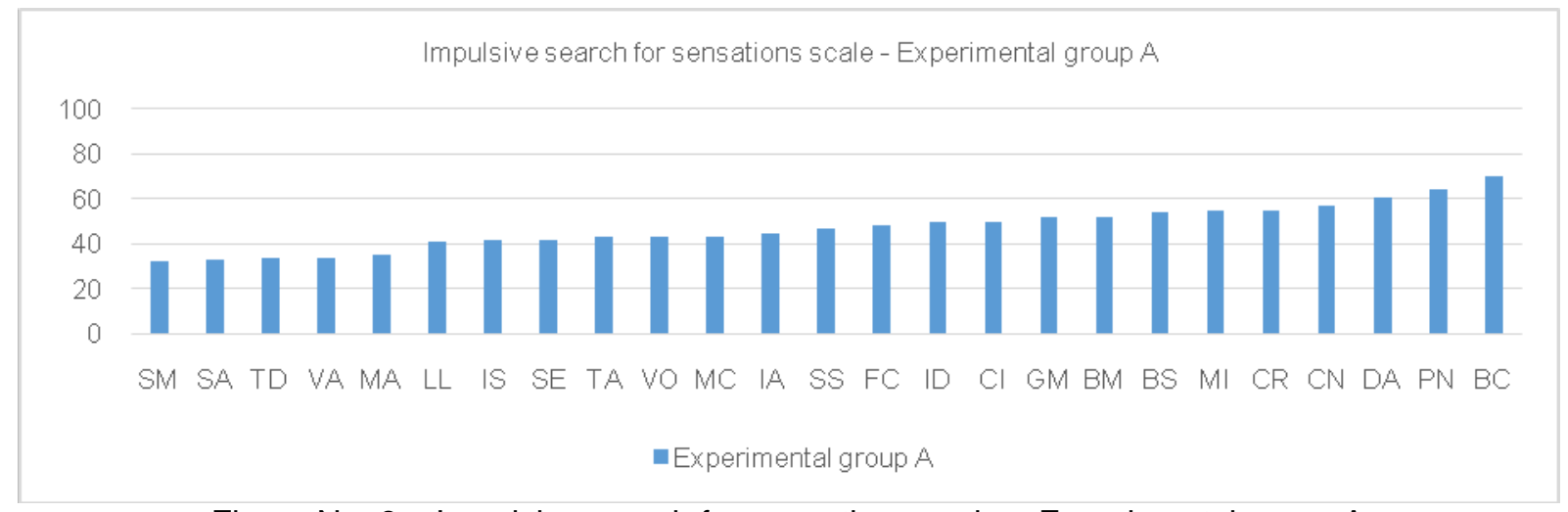

Figure No. 8 - Impulsive search for sensations scale - Experimental group A

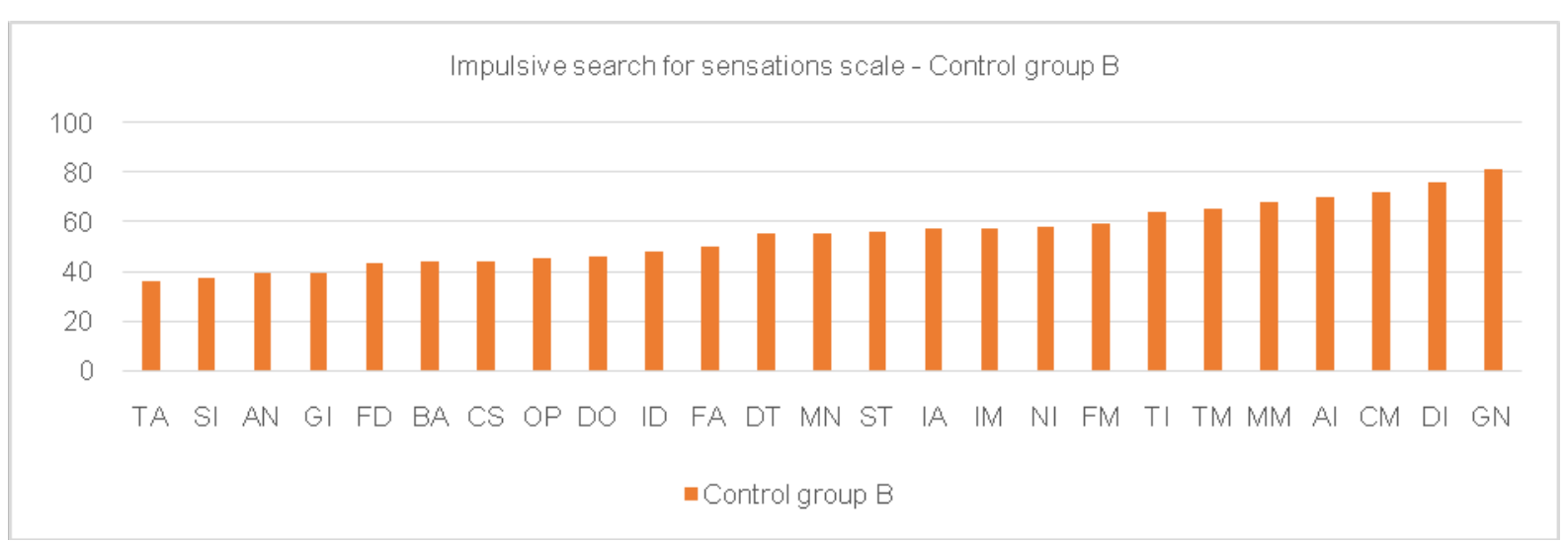

Figure No. 9 - Impulsive search of sensations scale - Control group B

\section{Aggressive-hostility:}

In the case of items that focused on aggressive, hostility scale, we watched subjects' inclination towards an increased level of aggression, both physically but mostly verbal. Subjects exhibit impulsive behavior, they don't have patience in interpersonal relationships, and they have a choleric temperament. Therefore analyzing the responses of the two groups, the control group, and the experimental group, we concluded that $56 \%$ of students in the experimental group and $48 \%$ of control group students have obtained a quota $\mathrm{T}$ below in the average population.

Applying the significance test T-test we noticed that the value of $t$ was 12.545046 , and thep valuewas 0.00001 , indicating a significant difference between the two groups of students, $p \leq 0.05$.

Analyzing the results of ZuckermanKuhlman test application on the aggression and hostility scale, we have seen that $32 \%$ of students from the experimental group have low hostility or aggression level. In the control group, we noticed a lower number of pupils who do not show aggression or hostility, over $24 \%$ from the total of students from the control group.

In the case of the experimental group $12 \%$ of all pupils achieved above-average results regarding hostility and aggression compared to a larger number of students, $28 \%$ of all students from the control group who exhibit these traits of aggression and hostility. 
"Mircea cel Batran" Naval Academy Scientific Bulletin, Volume XXI - 2017 - Issue 2 The journal is indexed in: PROQUEST I DOAJ / Crossref / EBSCOhost/ INDEX COPERNICUSI OAJI / DRJI I JOURNAL INDEX / I2OR / SCIENCE LIBRARY INDEX / Google Scholar I Academic Keys / ROAD Open Access I Academic Resources / Scientific Indexing Services / SCIPIOI JIFACTOR

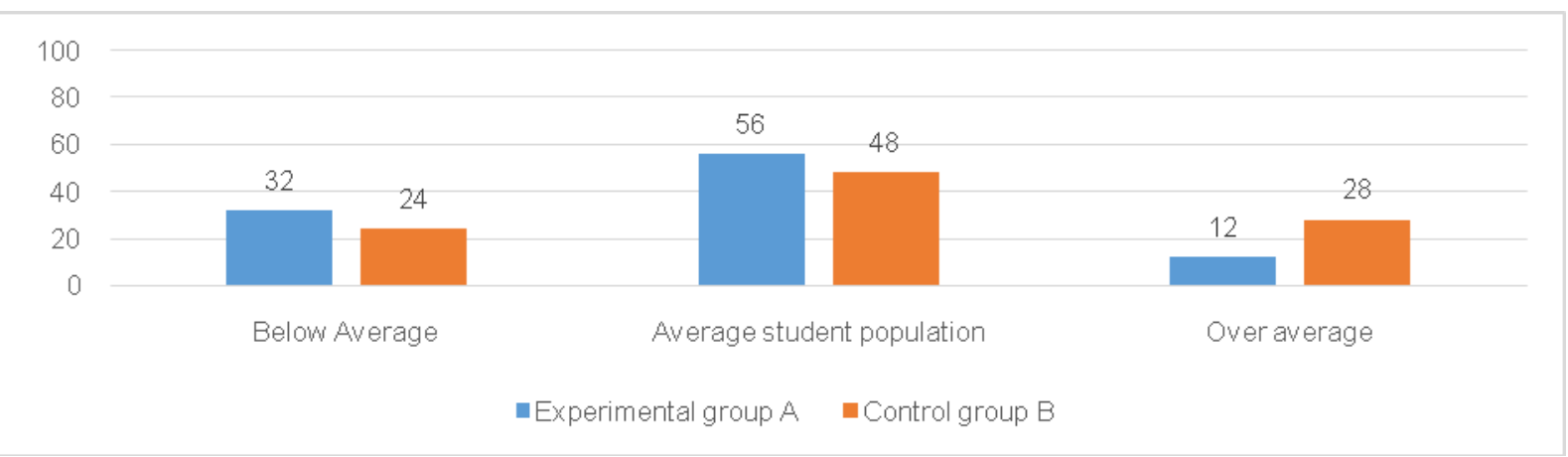

Figure No. 10 - Aggressive-hostility scale

Table No. 4 - Statistic indicators of Aggressive-hostility scale

\begin{tabular}{|c|c|c|c|c|c|}
\hline \multicolumn{3}{|c|}{ Experimental group A } & \multicolumn{3}{|c|}{ Control group B } \\
\hline Aggressive-hostility scale & Cases & $\%, N=25$ & Aggressive-hostility scale & Cases & $\%, N=25$ \\
\hline Below average (0-40T) & 8 & $32 \%$ & Below average (0-40T) & 6 & $24 \%$ \\
\hline Average population (40-60T) & 14 & $56 \%$ & Average population (40-60T) & 12 & $48 \%$ \\
\hline Over average (60-100T) & 3 & $12 \%$ & Over average (60-100T) & 7 & $28 \%$ \\
\hline Total & 25 & $100 \%$ & Total & 25 & $100 \%$ \\
\hline Mann-Whitney U Test & \multicolumn{5}{|c|}{ Z-score $=-2.3186 \quad$ U-value $=192.5 p$-value $=0.02034 \quad p \leq 0.05$} \\
\hline Test-T & \multicolumn{5}{|c|}{$\mathrm{p}$-value $=0.00001$ T-value $=12.545046 \quad \mathrm{p} \leq 0.05$} \\
\hline One-Way ANOVA & \multicolumn{5}{|c|}{ f-ratio $=6.5087 \quad p$-value $=0.013977 \quad p \leq 0.05$} \\
\hline
\end{tabular}

Aggressive-hostility scale - Experimental group A

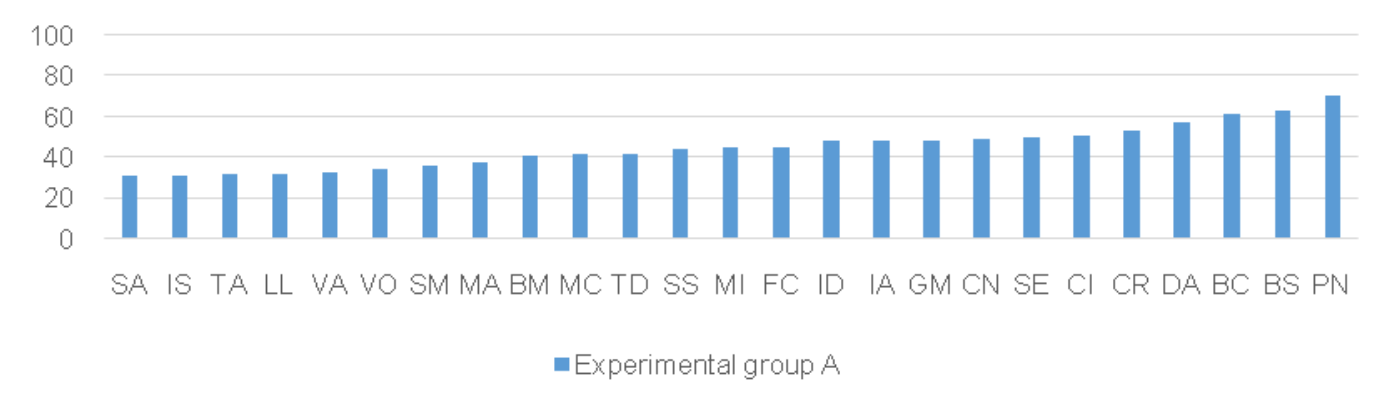

Figure No. 11 - Aggressive-hostility scale - Experimental group A

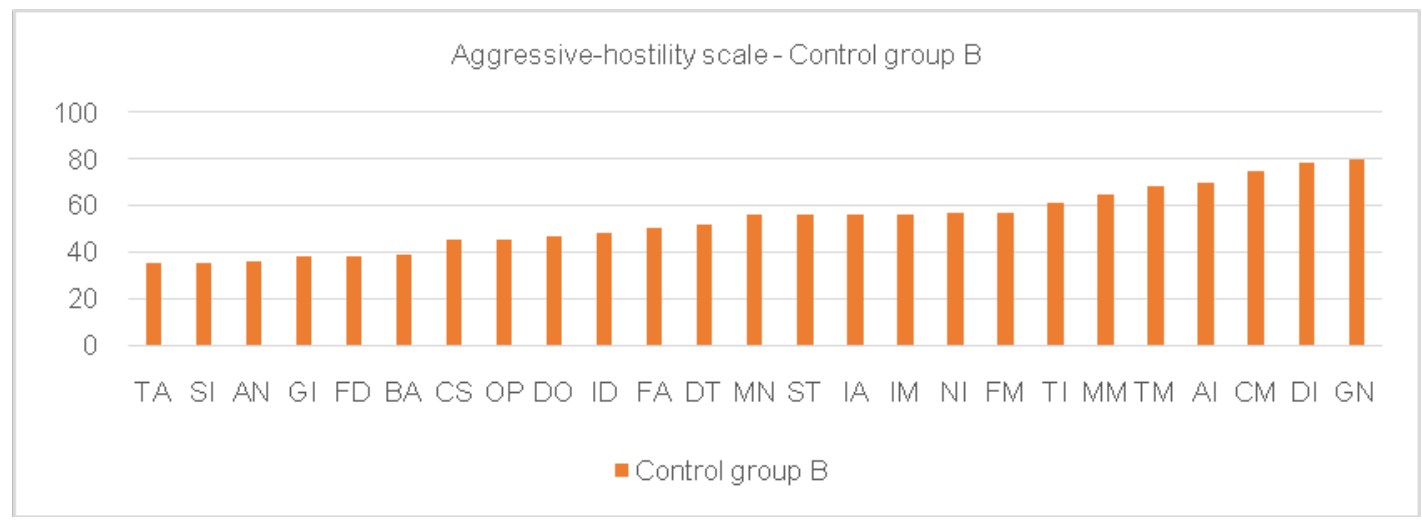

Figure No. 12 - Aggressive-hostility scale - Control group B

\section{Activity}

In the case of items that focused on the scale of activity, we watched the subject need to be active at all times, of working hard, subjects who prefer demanding activities with high energy consumption, the items showing 
"Mircea cel Batran" Naval Academy Scientific Bulletin, Volume XXI - 2017 - Issue 2 The journal is indexed in: PROQUEST I DOAJ / Crossref / EBSCOhost/ INDEX COPERNICUSI OAJI / DRJI I JOURNAL INDEX / I2OR / SCIENCE LIBRARY INDEX / Google Scholar I Academic Keys / ROAD Open Access / Academic Resources / Scientific Indexing Services / SCIPIO/ JIFACTOR

also the subject level of anxiety, impatience when they are inactive. Therefore analyzing the responses of the two groups, the control group, and the experimental group, we concluded that $48 \%$ of students in the experimental group and $56 \%$ of control group students have obtained a value of $\mathrm{T}$ below the average population.

Applying the significance test T-test we noticed that the value of $t$ was -0.303393 and $p$ value was 0.764205 , indicating a significant difference between the two groups of students, $\mathrm{p} \leq 0.05$.
Analyzing the results of ZuckermanKuhlman test application on activity scale, we have seen that $8 \%$ of the experimental group students are not very active. In the control group, we noticed a larger number of pupils who prefer not to work, $16 \%$ of the total number of students from the control group.

In the case of students who prefer sports activities, we have achieved high scores about $44 \%$ of the experimental group compared with $28 \%$ of those from the control group, which may indicate an increased desire for activity in the experiment group.

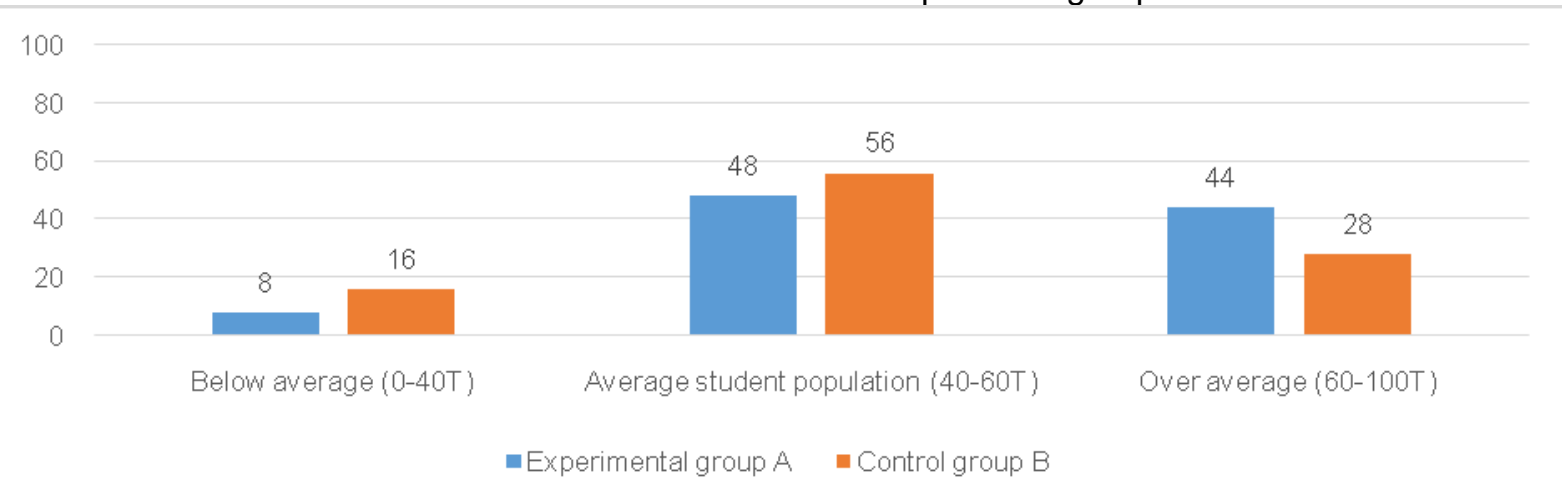

Figure No. 13 - Activity scale at Experimental group A and Control group B

Table No. 5 - Statistic indicators of activity scale

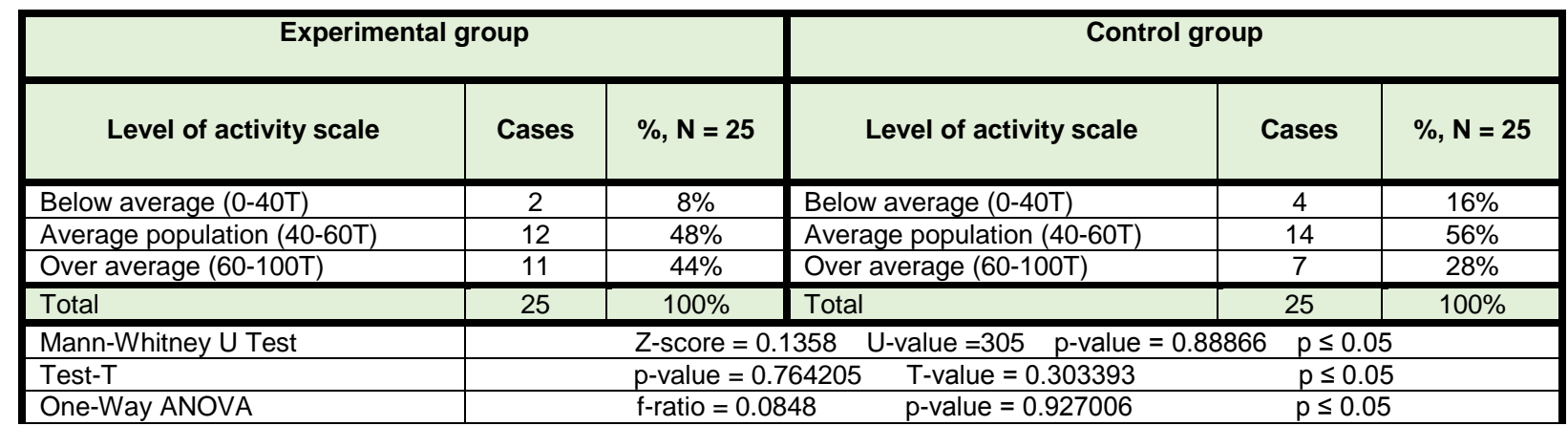

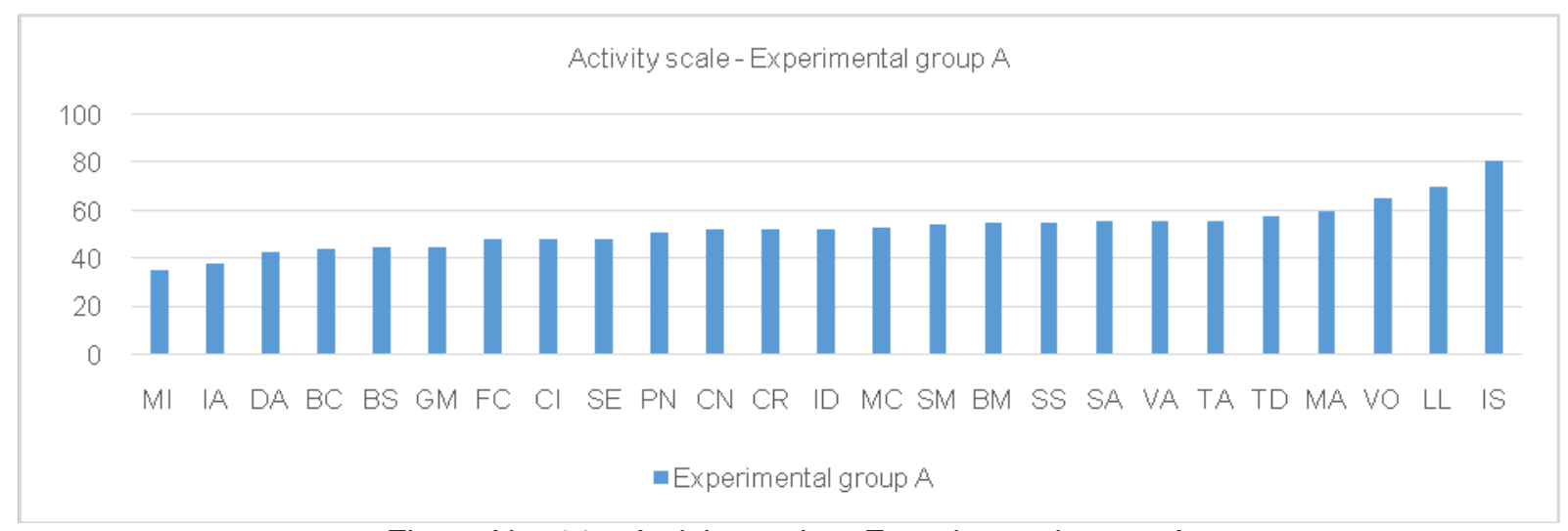

Figure No. 14 - Activity scale - Experimental group A 


\section{"Mircea cel Batran" Naval Academy Scientific Bulletin, Volume XXI - 2017 - Issue 2 The journal is indexed in: PROQUEST I DOAJ / Crossref / EBSCOhost/ INDEX COPERNICUSI OAJI / DRJI / JOURNAL INDEX / I2OR / SCIENCE LIBRARY INDEX / Google Scholar I Academic Keys / ROAD Open Access I Academic Resources / Scientific Indexing Services / SCIPIOI JIFACTOR}

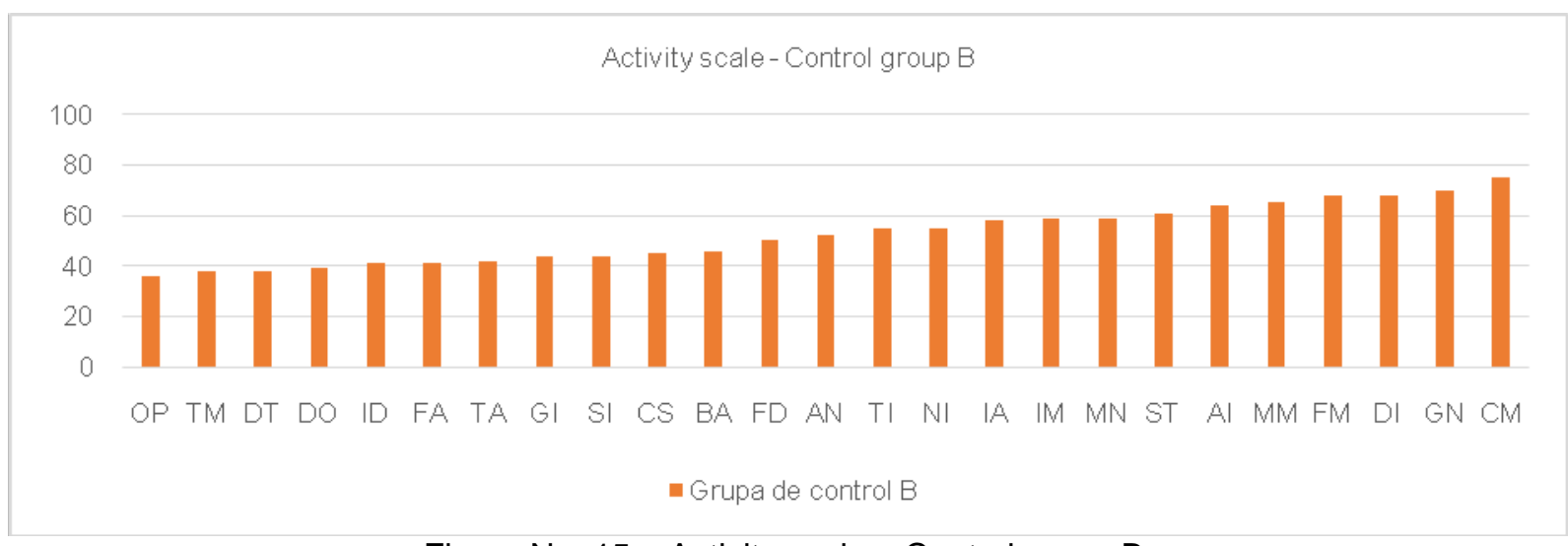

Figure No. 15 - Activity scale - Control group B

\section{CONCLUSIONS}

After the applying of differentiated programs on the two groups, we found using the ZuckermanKuhlman personality questionnaire, that students from the experimental group had a better level of sociability and social integration, lower levels of anxiety, are not so attracted to newer experiences, have a low level of aggressiveness and increased activity levels compared to the control group. So we can say that the research hypothesis, according to which "used as a research tool the ZuckermanKuhlman personality questionnaire can give us the opportunity to investigate the personality traits of students present in both the experimental and control group in terms of sociability and social integration, anxiety, look for sensations, the level of aggression and activity level", was validated, we can say that students in the experimental group who completed the training program with motor activities, playful and agonistic games, are as the questionnaire say, more sociable, applying the significance T-test we noticed that the p-value calculated was 0.00001 and the value of $T$ was 10.907800 , indicating a significant difference between the two groups, $p \leq 0.05$.

Also on the scale of neuroticism-anxiety we found that students in the experimental group had a lower level of anxiety and nervousness than students from the control group, applying the significance t-test, we noticed that the value of $T$ was 4.471485 , and the value $p$ was 0.000159 , indicating a significant difference between the two groups of students, $p \leq 0.05$. Therefore we can say that the motor activities carried out with the experimental group had positive effects, students in the experimental group increased levels of resistance to stress, mastering the situation, they did not quickly lose their temper, and have a lower level of anxiety.

Regarding the scale of "impulsive search for sensation", we noticed that the experimental group has a lower level regarding impulsivity in search of sensations, students are more calculated, more patient, and more careful, with a higher level of discipline compared with the control group. Therefore applying significance T-test we noticed that the value of $T$ was 11.037062 and $p$-value was 0.00001 , indicating a significant difference between the two groups of students, $p \leq 0.05$.

On the scale of "aggression-hostility" we can observe that students from the experimental group had a lower level of aggressivity and hostility compared to students from the control group, therefore applying the significance t-test we noticed that the value of $T$ was 12.545046, and the value of $p$ was 0.00001 , indicating a significant difference between the two groups of students, $p \leq 0.05$.

Looking at scale of "activity" we can see that both groups of students met an increased willingness for activity, children are willing to make as many sports activities, therefore applying significance T-test we noticed that the value of $T$ was -0.303393 and $p$-value was 0.764205 , indicating a significant difference between the two groups of students, $p \leq 0.05$.

\section{BIBLIOGRAPHY}

[1] Tufan, A., (2016), The impact of the motor activities on the education of a healthy lifestyle at students, PhD. Thesis UNEFS Bucharest.

[2] Sopa, I. S., Pomohaci, M., (2014 e), Contribution of sportive game in children socialization process. Scientific Conference "Physical education and sports in the benefit of health" - the $40^{\text {th }}$ Edition, Oradea.

[3] Sopa, I. S., Pomohaci, M., (2014, c), Study regarding the impact of sport competitions on student's socialization. Published in European Scientific Journal, Volume 10, No 26. 
"Mircea cel Batran" Naval Academy Scientific Bulletin, Volume XXI - 2017 - Issue 2

The journal is indexed in: PROQUEST I DOAJ / Crossref / EBSCOhost/ INDEX COPERNICUS/ OAJI / DRJI / JOURNAL INDEX / I2OR / SCIENCE LIBRARY INDEX / Google Scholar I Academic Keys / ROAD Open Access / Academic Resources / Scientific Indexing Services / SCIPIOI JIFACTOR

[4] Sopa I. S., Pomohaci, M., (2014, a), Developing Cohesion in Sportive Group through Socializing Means of Motor Activities. Published in: Medimond by Editografica, Bologna, Page 135.

[5] Grigore, V., (2007), Physical exercise. Active factor in preventing the aging and degenerative diseases installation, Editor Didactic and pedagogic. Bucharest.

[6] Sopa, I. S., Pomohaci, M., (2014, b), Group cohesion important factor in sport performance. Published in European Scientific Journal, Volume 10, No 26.

[7] Sopa, I. S., Pomohaci, M., (2015, a), Finding the leader of a volleyball team using the socio metric survey method. Published at the International Congress of Physical Education, Sports and Kinetotheraphy 5th Edition „Education and Sports Science in $21^{\text {st }}$ Century”, Bucharest.

[8] Sopa, I. S., Szabo, D. A., (2014), Study regarding the importance of developing group cohesion in a volleyball team. Published in: Procedia Social and Behavioral Sciences, Elsevier Publication, Volume 180C, 5 May 2015, Pages 1343-1350.

[9] Sopa, I. S., Pomohaci, M., (2015 b), Improving socialization through sport games. How does team sport affect children at primary school level. International Scientific Conference „Sport, Education, Culture - Interdisciplinary approaches in scientific research", Galati 28-30 May 2015.

[10] Sopa, I. S., Pomohaci, M., (2014 f), Study regarding group cohesion of students. The International Scientific Conference „Physical education and sports in the benefit of health”, Oradea.

[11] Sopa, I. S., (2014), The socializing role of motor activities at primary school level. Bulletin of the Transylvania University of Brasov, Vol. 7 (56) No. 2.

[12] Sopa, I. S., Pomohaci, M., (2014, d), Socialization through sport, effects of team sports on students at primary school level. Published in: Medimond by Editografica, Bologna, Page 351.

[13] Eysenck, H. J., (1985), The Biological Basis of Personality, Springfield, IL:Thomas, p. 681-706.

[14] Costa, P. T., McCrae, R. R., (1985), The NEO Personality Inventory, Odessa.

[15] Zuckerman, M., Kuhlman, D. M., Joireman, J., Teta, P., Kraft, M., (1993), A comparison of three structural models for personality: The Big Three, the Big Five, and the Alternative Five, Journal of Personality and Social Psychology, 65(4), 757-768. 